\title{
Development of Aerospace Engineering-Focused Undergraduate Research at a Small University: Accomplishments and Lessons Learned
}

\section{Dr. R. Danner Friend, Norwich University}

Dr. R. Danner Friend received his Ph.D. in Aerospace Engineering from Texas A\&M University in 1999. He then worked for Applied Research Associates in Alexandria, Va. prior to coming to Norwich University in 2003. He is currently an associate professor of Mechanical Engineering at Norwich. Some of the courses that he regularly teaches include Materials Science, Manufacturing, and Mechanical Engineering Tools. He enjoys mentoring undergraduate students in aerospace-related research projects. Some of the research areas include autonomous navigation of micro-space vehicles, underwater robotic vehicles, and design of experiments for testing new materials for spacecraft thermal protection systems.

\section{Dr. Jacques N Beneat, Norwich University}

Dr. Jacques Beneat received the Ph.D. degree in electrical and computer engineering from Worcester Polytechnic Institute (WPI), Massachusetts in 1993 with focus on advanced microwave structures for satellite communications. He is currently associate professor of Electrical and Computer Engineering at Norwich University in Vermont. He has been involved in undergraduate research for many years with international collaborations with the Ecoles militaires de Saint-Cyr and the University of Bordeaux in France, and the Ecole Polytechnique de Montreal in Canada. 


\title{
Development of Aerospace Engineering-Focused Undergraduate Research at a Small University: Accomplishments and Lessons Learned
}

\begin{abstract}
Involving undergraduate students in mentored research projects can provide a valuable, high impact educational experience while providing added benefits to faculty mentors, the institution, and the greater scientific and engineering community. This paper describes the evolution and successful strategies implemented in the development of aerospace engineering-focused undergraduate research at a small, undergraduate-level university. Undergraduate research can be challenging to implement in a small, teaching focused university with limited resources and no graduate school programs. Over a period of six years, the research program at Norwich University has evolved from one with very little aerospace-related undergraduate research activity to an active and sustainable program where students can contribute to research efforts in areas of critical need within the Aerospace community.
\end{abstract}

The research program has been built upon a model of undergraduate research established by the Council on Undergraduate Research (CUR) where research is broadly defined, faculty mentors are actively involved, and there is an expectation that the research processes and results will be disseminated through presentations and/or publications. An interdisciplinary, team approach has been emphasized with most of the aerospace-focused projects involving teams of students from both the Mechanical and Electrical and Computer Engineering programs. Students can participate in research related activities during the summer as well as during the school year. The primary funding has come from the Vermont Space Grant Consortium and Vermont's NASA EPSCoR Programs. Technical areas of the projects have included Optical Navigation, Nanosatellites, Image Processing, Autonomous Underwater Vehicle, and Inductively Coupled Plasma Torch Facility testing.

Some of the measures of success that are reported in this paper include the number and diversity of students involved in research activities, sustained funding received to support the research, collaboration with other universities, and the dissemination of research processes and results. One measure of success that is particularly noteworthy is the large number of student presentations at a variety of university and state level venues as well as prestigious national conferences. In addition to the successes, this paper addresses the challenges encountered and lessons learned during the process of building the research program. Notable lessons learned include collaboration with larger universities, keeping the scope of the project small, keeping the team sizes small, and incorporating an expectation that the outcome is more about students learning the research process versus producing results or having pressure to deliver a fully tested product.

\section{Introduction}

Small universities with primarily undergraduate programs have historically been teachingfocused with research being secondary or even non-existent. In recent years, there has been a shift toward involving undergraduate students in mentored research activities. The benefits and rewards for the students, faculty mentors, the institution, and the greater scientific and 
engineering community have been recognized, however there are many challenges to implementing a successful research program at the undergraduate level. Within the engineering education community, the topic of undergraduate research, and in particular the issues facing primarily undergraduate universities, have been addressed in several papers. ${ }^{1,2,3,4}$

In the past decade, a similar trend of increased undergraduate research activities has occurred at Norwich University, a small, teaching-focused university in the state of Vermont. This paper addresses the successes, challenges, and lessons learned in the development of aerospace engineering-focused research within the engineering school at Norwich.

\section{Profile of Norwich University and History of Student Research Program}

Norwich University has a student population of approximate 2300 with a student/faculty ratio of 14:1. The university is primarily an undergraduate teaching-focused school. The David Crawford School of Engineering consists of three departments offering the Bachelor of Science degrees in Mechanical, Civil, and Computer and Electrical Engineering. An online graduate program was started in 1997 and adds an additional 1200 students with the only graduate engineering program being a Master's degree in Civil Engineering. The undergraduate student population in the engineering school is approximately 270.

The student research program at Norwich was formally established in 2002. The mission of the university-wide research program is "To support and encourage our students to pursue original research, scholarship and creative projects in collaboration with faculty, and to provide funding to allow for exchanging of information and presentation of their work at professional meetings and within the University community.” Funding opportunities include Student Travel Grants, Student Research Grants, and Summer Research Fellowships. The university has a Director of Student Research who works in collaboration with a Student Research Committee and the Senior Vice President for Academic Affairs to administer the program. In 10 years, the university's research program has grown from only three students participating in summer research the first year to between 26 and 38 students each summer during the past three years.

The research program at Norwich has been built upon a model of undergraduate research established by the Council on Undergraduate Research (CUR) where research is broadly defined, faculty mentors are actively involved, and there is an expectation that the research processes and results will be disseminated through presentations and/or publications. A joint statement by CUR and the National Conference on Undergraduate Research (NCUR) in support of undergraduate research, scholarship, and creative activities describes undergraduate research as a “. . . a collaborative enterprise between student and faculty member-most often one mentor and one burgeoning scholar . ..” and includes “... the dispersing/sharing a new scholar's discoveries with his or her peers-a specific step traditionally missing in most undergraduate educational programs." 5

The culture of undergraduate research at Norwich has evolved over the past ten years with an increasing number of faculty involving undergraduate students in their research efforts. As part of this evolution, the authors have been collaborating to grow undergraduate research within the engineering programs in the Mechanical Engineering Department and the Electrical and 
Computer Engineering Department. Combining the research interests by the authors and financial support through the state's Space Grant and NASA EPSCoR programs, a sustainable aerospace-focused research program has been established.

\section{Opportunities for Students to Work on Research Projects}

Students have opportunities to work on research projects in one of three categories. The first category is a summer research fellowship. During the summer, a student can work full time as a summer research fellow for a period of six to ten weeks under the mentorship of a faculty member. During this time, the student cannot participate in summer school or a summer job. Students are paid a stipend of $\$ 10 /$ hour for their work. The summer program is an opportunity for students to take time to do literature reviews and background research that includes the previous year's work on the project. Building upon the previous year's work, the students use that foundation to investigate their own research question that will contribute to the overall advancement of the project.

Two other categories of research opportunities allow students to participate in the projects during the school year through either their senior design project or through independent research. Senior design projects involve students working on interdisciplinary teams, and the project must satisfy the design requirements of the course. Senior design teams working on the aerospace projects mentioned in this paper are expected to incorporate an applied research approach to identify some aspect of the research problem for which the design process can be applied. In a paper by Lemley et al., the authors have demonstrated how senior design projects can successfully integrate with research projects. ${ }^{6}$

The third option for working on research projects is the independent research option. Independent research is conducted during the school year and is not associated with a course. The students can be paid at an hourly rate with the number of hours limited to 10 hours per week.

\section{Aerospace-Focused Project Summaries}

There have been three main aerospace-focused projects that the students have been able to participate in. One of the projects involves students working on a miniature satellite called a CubeSat. Another project is the Autonomous Underwater Vehicle (AUV). The third project involves experimental design for an Inductively Coupled Plasma (ICP) Torch Facility. A technical summary is presented for each project.

Miniature spacecraft are becoming more popular due to their low cost and much smaller development times compared to larger spacecraft. CubeSats are a class of miniature spacecraft that have been designed primarily as satellites in low earth orbit with sensors that can take advantage of the proximity to the earth for attitude and position determination. Engineering students and faculty at Norwich are working on a CubeSat project in collaboration with two other institutions in the state, Vermont Technical College and the University of Vermont. A continuing goal of the CubeSat project is to investigate the feasibility of sending a triple CubeSat to the Moon. To make a lunar mission more economical, an autonomous navigation system is a requirement for the mission. Goddard Space Flight Center has developed a navigation system 
called GEONS (GPS Enhanced Onboard Navigation System) that can provide autonomous orbit determination for the lunar mission. When the spacecraft is outside of GPS range, GEONS provides a navigation solution that relies on sensor measurements of line-of-sight (LOS) unit vectors from the spacecraft to celestial bodies such as the sun, planets, and the Moon. The potential sensors include cameras, sun sensors, and a miniature star tracker. The part of the project that Norwich is working on is the sensor selection and image processing required to provide the LOS vector input into GEONS. The main technical areas for the CubeSat research at Norwich can be summarized into four main areas: (1) autonomous navigation, (2) celestial navigation, (3) optical sensors, and (4) image processing. There are more detailed research questions, goals and objectives associated with each of these technical areas that are not given in this paper for the sake of brevity. A selection of images related to the CubeSat project is given in Figure 1.

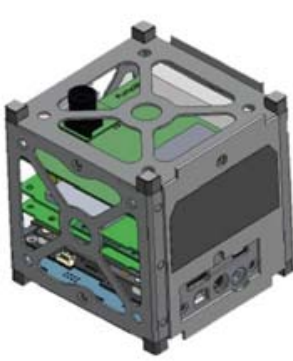

(a)

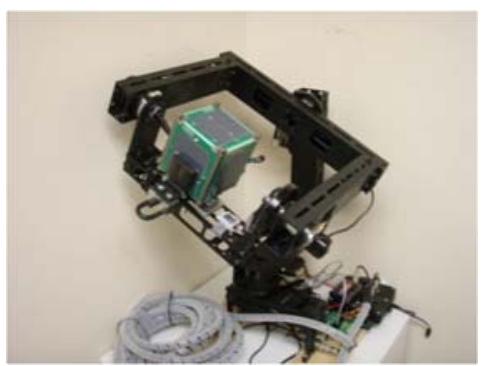

(b)

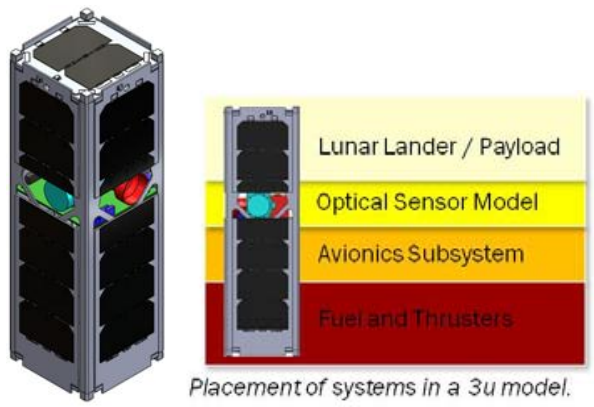

(c)

Figure 1. Autonomous Navigation Using Optical Sensors for a CubeSat Lunar Mission.

$\begin{array}{llll}\text { (a) Single CubeSat Test Model } & \text { (b) Dynamic Test Platform } & \text { (c) Triple CubeSat Model for Lunar Mission }\end{array}$

The CubeSat project started in 2010 and is an active, multiyear project that builds off of the previous year's work. Since January 2010, a total of 21 undergraduate students have worked on the CubeSat project under the mentorship of two faculty members (Mechanical and Electrical \& Computer Engineering). Among these students, seven started as a summer research fellow, and then five of those seven students applied the results of their research in their capstone senior design project.

The second project involves students working on an Autonomous Underwater Vehicle. The original motivation for this project comes from NASA's interest in Europa, a large moon of Jupiter, which has a large liquid ocean beneath its ice crust. The liquid ocean is believed to have the necessary conditions to support life. To investigate the ocean, an underwater vehicle would require an autonomous navigation capability. Norwich is working on the development of a vision system that will allow an underwater vehicle to navigate autonomously.

After only one year, the first underwater vehicle was entered into the annual international RoboSub competition hosted by Autonomous Unmanned Vehicle Systems International (AUVSI) and the Office of Naval Research (ONR). The AUV received the most innovative design award of that year, however the vehicle failed to perform due to equipment malfunction. Part of the equipment failure was attributed to lack of sufficient time for testing and troubleshooting the AUV before the competition. The following year it was decided that a modular platform was needed to support future iterations of underwater vehicles while 
maintaining a central platform. This concept led to the creation of the current underwater vehicle platform called Leviathan. Although the majority of testing has occurred in the university's pool, the potential exists for testing in the nearby Lake Champlain. The lake is frozen for much of the school year which makes for ideal conditions to emulate the conditions found on Europa. Images of the original AUV design and the current AUV, "Leviathan”, is given in Figure 2.

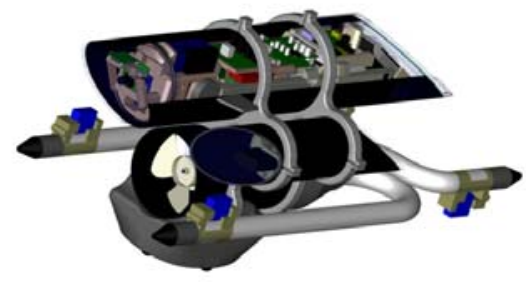

(a)

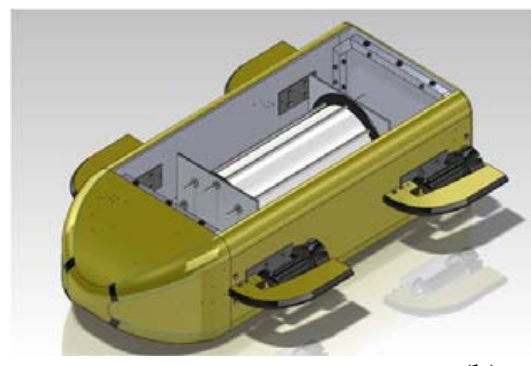

(b)

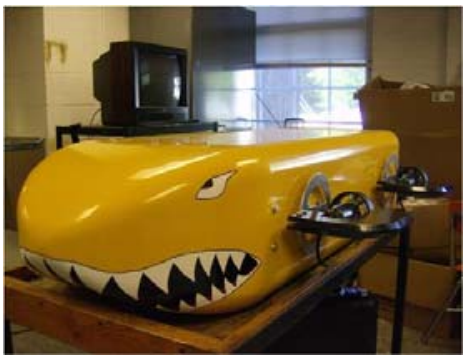

(b) Current AUV (“Leviathan”)

The AUV project started in 2007 and is an active, multiyear project that builds off of the previous year's work. Since 2007, a total of 21 undergraduate students have worked on the project under the mentorship of three faculty members (Mechanical and Electrical \& Computer Engineering). Four of these students started as a summer research fellow.

The third project that our students have worked on involves a $30 \mathrm{~kW}$ inductively coupled plasma torch (ICP) facility that has recently been developed at the University of Vermont (UVM). The purpose of the ICP facility is to conduct research in the testing of new materials to be used for the thermal protection systems for the next generation of space exploration vehicles. Part of a greater project called "Investigation of Critical Aerothermodynamic Phenomena for Hypersonic Vehicles", the contribution from Norwich has been to support the development of the new ICP torch facility. The aerospace industry uses ICP torch facilities to simulate the extreme conditions that a vehicle will experience when going through the earth's or another planet's atmosphere. By using a mixture of different gases, atmospheric conditions for specific planets can be simulated. In anticipation of future Mars exploration missions, the ICP torch facility at UVM was designed specifically to be able to simulate atmospheric conditions for space vehicles entering the Mars atmosphere. Projects that Norwich students have worked on include the following: (1) Watercooled sample holder, (2) PC-based control and monitoring system that automates the actuator inputs and sensor outputs, (3) Investigation of a Rogowski Coil for Measuring Peak Voltage, (4) Pitot Pressure and Heat Flux Measurement Using a Calorimeter, and (5) Fiber Optic-Based Measurement of Total Radiant Heat Flux. A selection of images related to the ICP project is given in Figure 3. 


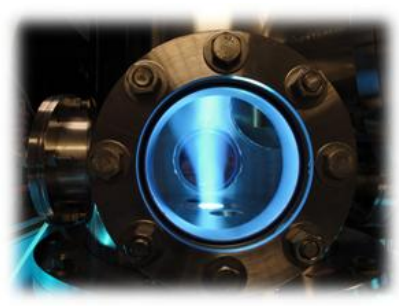

(a)

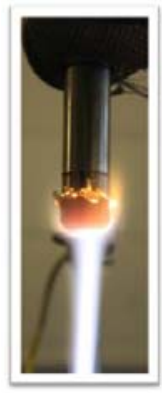

(b)

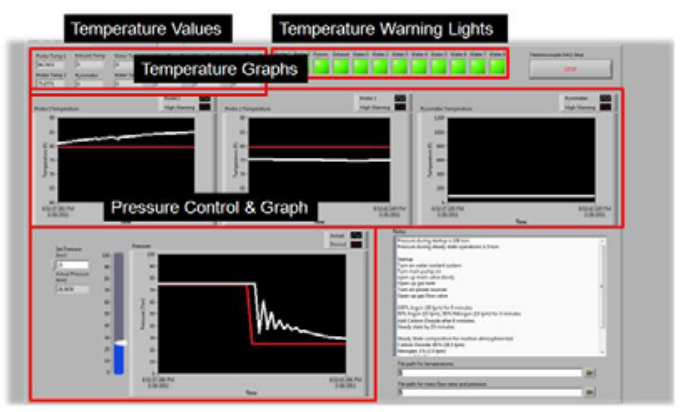

(c)

Figure 3. Inductively Coupled Plasma (ICP) Torch. (a) ICP Main Test Chamber

(b) Testing of Water-Cooled Sample Holder $\quad$ (c) Temperature/Pressure Monitoring System

The ICP project is no longer an active project as the funding for the project came to an end in 2011. Between 2007 and 2011, a total of 12 students worked on the project under the mentorship of one faculty member (Mechanical Engineering). Four of these students initiated their work on this project as a summer research fellow.

In summary, during the six year period between January 2007 and January 2013, a total of 54 engineering students have participated in the three research projects.

\section{Funding Sources}

The funding for student research has come from two main sources: (1) Vermont Space Grant Consortium and (2) Vermont's NASA EPSCoR program. In addition, Norwich's internal fellowship program was used to initiate the AUV research project and at times provides additional small funds when needed. Follow-on funding for the AUV project came from the Vermont Space Grant Consortium, the CubeSat project was funded through the Vermont Space Grant Consortium, and the ICP torch project was funded through Vermont's NASA EPSCoR Program. The funding amounts were approximately $\$ 30 \mathrm{~K}$ for each project spread out over a three year period resulting in about $\$ 10 \mathrm{~K}$ per year per project.

It would have been difficult to have started working on the CubeSat and ICP projects without having been part of a collaborative effort with other universities. For example, our work on the vision system for the AUV project led to an invitation to join a group of universities that were applying for Space Grant funding for the CubeSat project. When the funding from the initial award was exhausted, follow-up funding was granted to continue the work. Going forward, funding of up to $\$ 10 \mathrm{~K}$ per year is available in our current grant to support both the CubeSat and the AUV project through 2015. Although funding beyond 2015 has not been approved yet, it is expected that future funding proposals to NASA to support Vermont Space Grant Programs will include a budget for continuing student mentored research at Norwich. The ICP project funding came about similarly by accepting an invitation from a team of faculty at the University of Vermont to be part of a NASA EPSCoR proposal. No additional funding is expected for the ICP project. 
As part of the requirement for funding through the NASA's Space Grant program, states must demonstrate how their programs align with NASA's educational outcomes. NASA educational outcomes that have been emphasized in our research program include interdisciplinary teams and diversity (inclusion of female and underrepresented minority students).

\section{Interdisciplinary Teams}

Both the CubeSat and AUV projects have involved interdisciplinary teams consisting of students from both the Mechanical (ME) and the Electrical \& Computer Engineering (ECE) departments. The breakdown of students from each department consists of 11 ECE and 10 ME students that have worked on CubeSat, and 13 ECE and 8 ME students that have worked on AUV. Both the CubeSat and the AUV projects are good projects to promote interdisciplinary teamwork. In the CubeSat project, the ultimate goal was to design, build and test a customized camera board suitable to withstand space temperatures and launch vibrations, to have suitable camera lenses and camera positioning to accommodate limited physical space, and to deal with limited computing and electrical power. The computer engineering students developed onboard camera programs, the electrical engineering students defined pull up, shunt resistors, and other electrical interconnection needs to the motherboard, and the mechanical engineering students selected the lens, camera needs, and camera positioning that maximized the chances of taking pictures of the Moon.

In the AUV project, the ultimate goal was to design, build and test a rugged submarine platform that can navigate under the ice crust autonomously. The computer engineering students defined the algorithms for autonomous navigation that included controlling thrusters and processing sensor data. The electrical engineering students calibrated the sensors and managed power consumption and electronic device selections. The mechanical engineering students designed and constructed watertight enclosures for the electronics, a rugged hull, and the propulsion system. All the tasks were part of a coordinated effort: The mechanical engineering students needed to know the size and composition of all electronics (onboard computer, sensors, thrusters, motor controllers), so they could design a platform with suitable center of gravity and buoyancy for a submarine. The electrical engineering students needed to test the thrusters and sensors in the water so they could calibrate the basic I/O programs that were used by computer engineering students to implement their autonomous navigation algorithms. The approach to the entire project (e.g. using feedback based algorithms rather than use of absolute value of measurement data) is a direct consequence of dealing with non ideal characteristics of practical computer/electrical/mechanical designs and fabrications.

\section{Diversity}

The percentage of female engineering students in each of the engineering departments is very small, and there are times in which there have only been a few female students in each engineering class. However, female students have been included in the research projects every year. For example, of the 21 students who have worked on the CubeSat project, five were female students. It's possible that female undergraduate students at Norwich might be more interested in summer research fellowships than the male students that seem to be more attracted to industry internships. Minority students also represent a very low percentage in our 
engineering programs, and there has been one minority student each year for the past three years working on the CubeSat project.

The inclusion of international students has also been a consistent part of the program. As part of a foreign exchange program, French students regularly complete a three month capstone project at Norwich. Students from Thailand are also regularly attending our engineering programs and participating in the aerospace research projects. Both bring solid analytical skills that are a good complement to the creativity and hands-on skills of our own students. However, verbal and written communications can be an issue. On team projects, the foreign students work together with other students who can help them with the oral and written reporting.

\section{Collaboration}

Collaboration with other universities has been an essential component of two out of the three projects. The students working on the ICP torch project benefited from working with a graduate student from UVM. The graduate student was working on his own research related to the ICP torch, and he acted as the technical advisor to the students. The students also benefited from being close enough to UVM that they were able to make multiple day trips to the torch facility when they were in the process of installing and testing their control system. It is worth noting that although the research effort of our students represented a small fraction of the overall project, the students were able to make a significant contribution to the advancement of the development of the torch facility.

The CubeSat project involves collaborations with two other universities. The majority of the collaboration occurred with Vermont Technical College, another small, teaching-focused institution. Our contribution in the area of autonomous navigation has been a small but integral part of the overall project. The students were able to work on their own part of the project, but were also required to see how their part integrated with the overall effort. In order to facilitate better collaboration, the project established a shared website using the Assembla cloud platform for sharing documents and an email list serve for discussion and daily updates.

\section{Dissemination of Results}

Part of the goal of the student research program was to establish an expectation that the project must include a final product for which the process and results are shared with the greater community. This product can take on many forms including oral presentations, poster presentations, and publications in conference proceedings and journals. This product is in addition to the required internal deliverables that include a final written report and oral presentations. All summer research fellows are required to present a poster at the University's Scholarship Celebration event held each year in the fall following the summer in which their work was completed. The posters are included as part of the faculty's scholarly work on display at the event. In addition, summer research work that has been funded by the Vermont Space Grant Consortium is presented by the students as a poster and an oral presentation at the annual Space Grant Awards Ceremony. On a national level, beginning in 2010, the students began presenting the results of their work at the National Conference on Undergraduate Research (NCUR) held each spring. Additional national level venues where their work has been 
presented include the ASME International Mechanical Engineering Congress and Exposition, AIAA Aerospace Sciences Meeting, and ASME Student Professional Development Conference. The presentation at the AIAA meeting also included a peer reviewed paper with the student as the first author. ${ }^{7}$

\section{Challenges}

Many of the challenges that come with implementing an undergraduate research program are not unique to our institution and are common among other primarily undergraduate institutions. Some of the more significant challenges are summarized here. Most of our undergraduate students have never participated in a research project before, and the mentor must spend a lot of time working through the research process with the student. There is often a steep learning curve that must be overcome before productive results can be expected. Unlike graduate students who have a more extended timeframe to work on research projects, the time that undergraduate students have to work on a project is often limited and rarely extends beyond one year. For continuing projects, the transfer of knowledge is also limited when there is not a lot of overlap between new students and departing students. Depending upon what year the student is in, the background and fundamental knowledge may be very different and the scope of the project will need to be adjusted accordingly. Also, the maturity of the students can vary greatly. Lack of responsibility is often encountered in undergraduate students resulting in reluctance to allow them to use expensive equipment without supervision.

Limited resources to support and conduct research represent a significant challenge, as it is for many small universities. The resources that have been minimal or non-existent include the following: Dedicated lab space (includes expensive research equipment that needs to be protected from misuse), technician help to set up and maintain advanced research equipment and software, and the acquisition and maintenance of accessories for specialized research equipment.

A majority of students choose to live a military lifestyle at Norwich University and often have additional obligations in the summer related to Reserve Officer Training Corps requirements. Their summer training would normally not allow them to participate in a 10 week, full time summer research program. In order to give these students an opportunity to also do summer research, a six week option was implemented to help attract more students who would otherwise not be able to participate in the summer research program.

\section{Lessons Learned}

This section lists a summary of the lessons learned during the six year period that the three aerospace projects have been conducted.

(1) Collaboration with other, larger schools can be very beneficial. The ICP torch project worked very well when the students were able to work with a graduate student as their technical mentor. This collaboration also allowed students to have more resources available to them that would otherwise not be available. Collaboration with a research institution that has graduate students doing research is mutually beneficial to the graduate student and to our students. However, collaboration with another undergraduate-only 
institution is not as beneficial since both institutions have the same type of students that have similar needs and lack of experience.

(2) Keep the teams small. Large teams of undergraduate students that all have similar experiences, capabilities, and maturity have not worked out very well. Some of the students think that they don't have to do very much work or think that someone else on the team will do the work. With smaller teams, each of the students wants to take ownership in the project. Also, if the teams are smaller, the faculty are able to devote more individual time to mentor the students.

(3) Keep the scope of the individual projects small. For funding purposes, the scope of a project (e.g. AUV or CubeSat) is often large, however the scope of each individual student project needs to be very narrowly defined. The first year's AUV project had a very large scope to build an entire AUV system that would need to be fully tested and ready for competition in one year. The pressure to complete the large project and deliver the final product for a competition was very stressful on the students and resulted in many of the senior design course deliverables not being met. It is much better to start with research project's overall goals and objectives and break the project down into small components with research questions and design goals that the students can actually accomplish over a summer or within a school year. Also, it is recommended not to participate in competitions that require large, complex systems like AUV to be built, tested, and ready for competition.

(4) Get students started with Summer Research that can lead to a senior project. This model can work well with a careful student selection process. Choose students that are capable of independent research and don't need constant guidance. They gain the experience and maturity that can transition them into team leaders on a senior project. Another advantage is that the continuity of the project continues throughout the year. The problem has been that due to small numbers of students and competition with other summer activities such as internships, summer school, and military training, there is not always enough interest in summer research. Recently, a six week summer research option, instead of the full 10 week option, has allowed some students to participate on a more limited basis and allow them to fulfill their other summer obligations.

(5) Because undergraduate students are limited in terms of their background experience and ability to work through complex problems, the faculty must carefully define what to ask the students to do. Senior students can handle more than sophomores, so the students and the project complexity must be matched accordingly. At the same time, due to the lack of graduate students, the faculty must take on parts of the research work on their own. For example, in the CubeSat project the complexity of the orbital mechanics and celestial navigation algorithms was too much for the students to work through. As a result, one of the faculty mentors spent a summer working on a particularly challenging aspect of the problem so that the overall research goals of the project could be advanced. Also, due to 
lack of graduate students, the faculty must learn the latest technologies involved in these projects so they can better estimate what the undergraduate students can successfully achieve and be better prepared to help them with technical issues.

(6) By using a teaching model for conducting undergraduate research, one of the major outcomes is the education of the students. The teaching loads, service loads, and teachingfocused culture at our institution make it very challenging to perform fundamental research. Mentoring undergraduate students in research during the summers takes away a considerable amount of time that could have been used for fundamental research. On the other hand, undergraduate research is very valuable for improving one's teaching career. For example the undergraduate research activities allow the faculty to learn modern technology and modern problems that eventually trickle down into the classrooms. Being in the business of teaching, undergraduate research can be looked upon as teaching students the skills and knowledge on how to conduct research. These skills will most likely benefit the student more than the faculty's research interests since undergraduate students are gone by the time they start becoming productive. This might be different than in a research institution where undergraduate research project needs are fulfilled by adapting ongoing fundamental research projects to fit the level of undergraduate students, but that their main goal is to keep ahead in fundamental research with graduate students.

\section{Conclusions}

Measures of success and lessons learned in the development of an aerospace-focused engineering research program in a small, teaching university have been discussed in this paper. Some of the measures of success include sustained student involvement in the projects, involving female and international students, the interdisciplinary team-based approach to the projects, sustained funding to support at least two summer research students each year, and the dissemination of results not only locally and statewide but also at national venues.

Some of the lessons learned for building a successful program at Norwich University include collaboration with larger, research universities, keeping the scope of the project small, keeping the team sizes small, keeping the continuity of the projects going throughout the year and from year to year, and incorporating an expectation that the outcome is more about students learning the research process versus producing results or having pressure to deliver a fully tested product.

\section{Acknowledgements}

The authors would like to thank the NASA Space Grant Program, Vermont Space Grant Consortium, and Vermont's NASA EPSCoR Program for funding student mentored research at Norwich University. In addition, special thanks goes to Dr. William Lakin, director of Vermont's Space Consortium and NASA EPSCoR programs, for his support and funding coordination efforts, Dr. Douglas Fletcher and Walt Owens for ICP torch project collaborations with the University of Vermont, and Dr. Carl Brandon for CubeSat project collaborations with Vermont Technical College. 


\section{Bibliography}

1. Robert D. Engelken, "Participation of Undergraduates in Engineering Research: Evolving Paradigms over Three Decades of Change," 2010 ASEE Annual Conference and Exhibition.

2. Eric Larson and Agnieszka Miguel, "Performing Engineering Research at Non-Ph.D. Granting Institutions,” 2007 ASEE Annual Conference and Exhibition.

3. Peter Schuster and Charles Birdsong, "Research in the Undergraduate Environment,” 2006 ASEE Annual Conference and Exhibition.

4. Robert D. Engelken, "Engineering Research at Predominately Undergraduate Institutions: Strategies and Pitfalls for the New Engineering Educator,” 1999 ASEE Annual Conference and Exhibition.

5. Council on Undergraduate Research/National Conferences on Undergraduate Research, "Joint Statement of Principles in Support of Undergraduate Research, Scholarship, and Creative Activities,” NCUR Board of Governors and CUR Governing Board (2005). www.cur.org/about_cur/history/joint_statement_of_cur_and_ncur/ (Accessed 7 April 2013).

6. Evan Lemley et al., "Linking Senior Design Projects to Research Projects,” 2010 ASEE Annual Conference and Exhibition.

7. Joseph Sargent and R. Danner Friend, "Control and Monitoring System for an Inductively Coupled Plasma Torch System,” 50th AIAA Aerospace Sciences Meeting, Nashville, Tennessee (Jan. 9-12, 2012). 